\title{
Study on characteristics of noise of diesel locomotive
}

\author{
Yingnan $\mathrm{Hao}^{1, a}$, Yan Liu ${ }^{1}$, Xiaopai Zhang ${ }^{1}$ and Zhifang Zhong ${ }^{1}$ \\ ${ }^{1}$ Institute of Transportation Engineering of Dalian Jiao tong University in Liaoning, China
}

\begin{abstract}
Noise test has been done for a certain type of diesel locomotive under different working conditions for outfield and cab, and analyzed the noise characteristic of each test point. Through the analysis of the data :The sound pressure level of point D, E, I, J of 12 test points of outfield test is bigger due to the effect of noise source; The changing of working condition of locomotive mainly makes test points of the outfield produce big change in the high frequency after $400 \mathrm{~Hz}$; The opening of cooling fan makes sound pressure level of test points of outfield improved obviously; The noise of cab is mainly produced by combined action of vibration of locomotive wall and external noise source: External noise source influences the whole frequency band of the cab, vibration makes individual frequency have big increased.
\end{abstract}

\section{Introduction}

Diesel locomotive noise issues mainly include outside noise caused by diesel locomotive sound radiation and the noise of the diesel locomotive cab.

With the progress of science and technology and the increasing environmental protection consciousness, the diesel locomotive noise has become an important indicator to assess the performance of diesel locomotive. Improving the acoustic environment surrounding the diesel locomotive, ensuring cab comfort as well as the passenger's body health has become one of the major problems must be solved.

Therefore, understanding the noise characteristics of diesel locomotive has important guiding significance for the design of diesel locomotive vibration noise reduction and improving driving environment of the passenger [15].

\section{Outfield noise test of diesel locomotive}

\subsection{Test equipment}

The analysis system of noise and vibration test includes SQ Lab II 60 channel data acquisition recorder and the front end, HMS III binaural signal collector, HPS IV digital back into the system, acoustic sensors, Artemis analysis software and so on.

\subsection{Test conditions}

In the test of diesel locomotive distribution of sound pressure level of outfield, according to the Australian acoustic test standard AS 2377-2002 and the actual needs, the test conditions for the diesel locomotive should be housekeeping, no-load, diesel engine gear is $0,4,8$; Diesel locomotive be housekeeping, load, diesel engine gear is $0,4,8$.

\subsection{Test points distribution}

According to the requirements of AS 2377-2002 standard, the height of each test point distance from the ground is $1.2 \mathrm{~m}$, the distance from locomotive is $15 \mathrm{~m} \mathrm{[6].} \mathrm{The}$ distribution of the specific test points are shown in figure 1 .

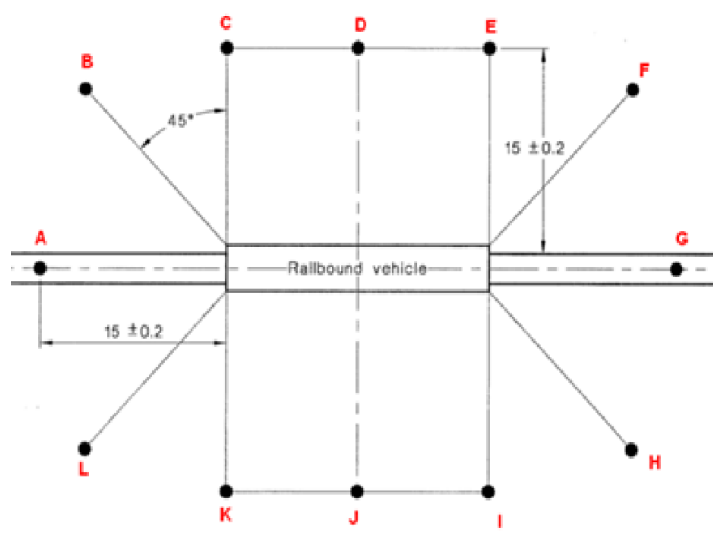

Figure 1. Diesel locomotive outfield test point distribution

\subsection{The test results analysis}

As figure 2 and figure 3 shows, the sound pressure of point $G$ increased significantly when conditions changed from no-load to load, this is mainly because point $G$ is close to the cooling chamber, the sound pressure level is

\footnotetext{
a Yingnan Hao: 1397006931@qq.com
} 
greatly influenced by the cooling chamber. When the test condition is no-load, the cooling system which in the cooling chamber doesn't work, the sound pressure level of point $\mathrm{G}$ is relatively low; when the condition change to load, the cooling system which in the cooling chamber is up and running, significantly increase the sound pressure level of point G. Analogously, point E, F, H and I are greatly influenced by the cooling chamber, when the condition change to load the sound pressure level of these points all have varying degrees of increase. Point B, C, J, $\mathrm{K}$ and $\mathrm{L}$ are greatly influenced by the diesel engine, when conditions change from no-load 8 file to load 0 file, the sound pressure level has different degrees of decline. The speed of the diesel engine reduces greatly when the diesel engine gear change from 8 to 0 file, the noise generated by the diesel engine has a sharp decline, thus the sound pressure level of points greatly influenced by diesel engine will have varying degrees of decline.

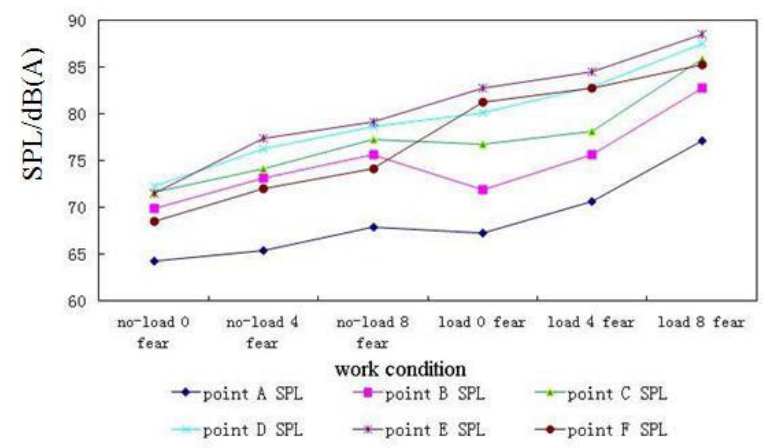

Figure 2. Point A-F sound pressure level at various conditions

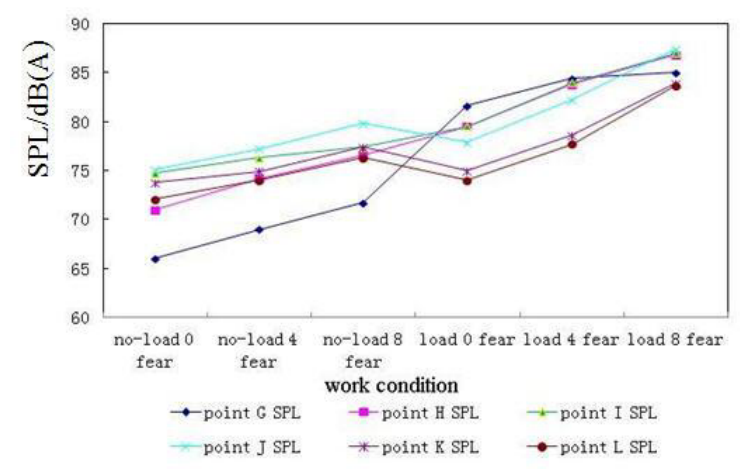

Figure 3. Point G-L sound pressure level at various conditions

The analysis system of noise and vibration test includes SQ Lab II 60 channel data acquisition recorder and the front end, HMS III binaural signal collector, HPS IV digital back into the system, acoustic sensors, Artemis analysis software and so on.

As analysis above shows, the sound pressure level of point D, E, J, I are bigger in 12 test points.

As can be seen from the figure 4 to 7 , when the working condition of the same gear changes from no-load to load, each test point has different amplitude increases in the intermediate frequency and high frequency after $1000 \mathrm{~Hz}$, the amplitude which increases is associated with the extent of the test point influenced by the cooling chamber. This shows that the radiation noise of cooling chamber gives priority to the high frequency noise. Point
E and I are greatly influenced by the cooling chamber, when the condition changes to load, the sound pressure level of same gear increases greatly in the frequency spectrum after $1000 \mathrm{~Hz}$.

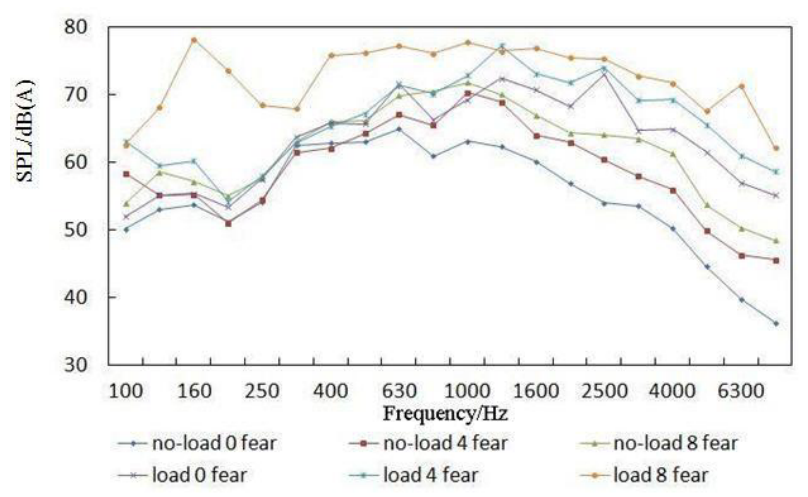

Figure 4. Point D sound pressure level spectrum diagram

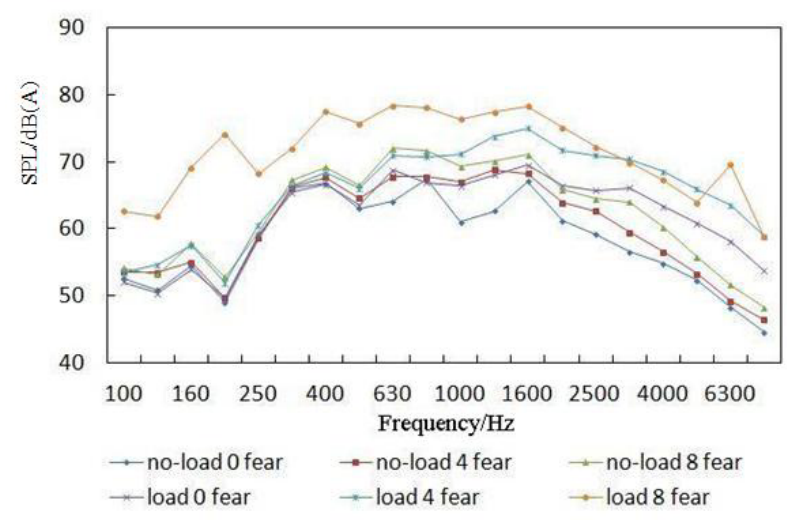

Figure 5. Point J sound pressure level spectrum diagram

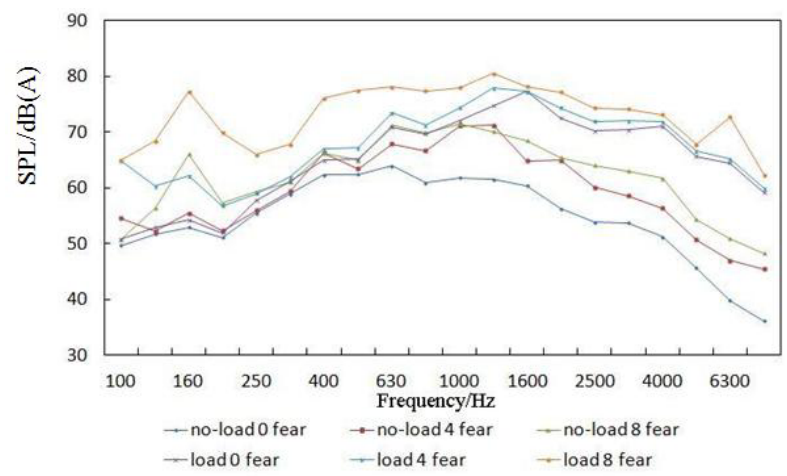

Figure 6. Point E sound pressure level spectrum diagram

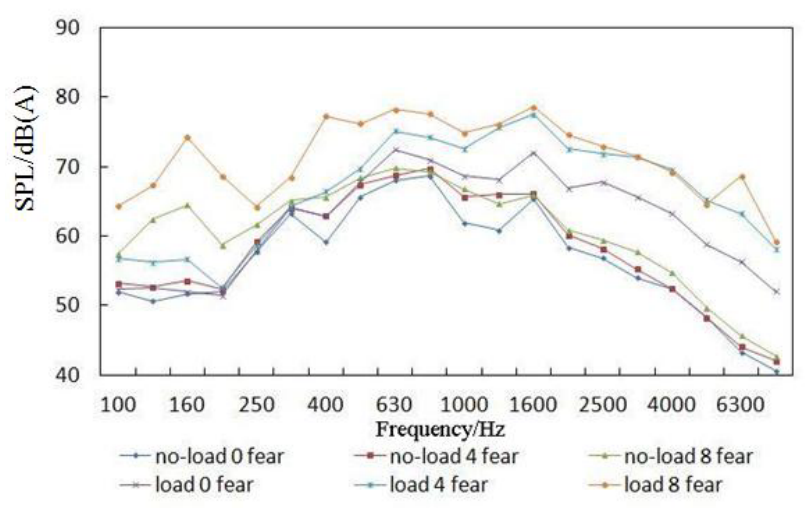

Figure 7. Point I sound pressure level spectrum diagram 
At gear0, gear4 and no-load gear8, the sound pressure level doesn't have big difference at $200 \mathrm{~Hz}-400 \mathrm{~Hz}$, the low frequency part of locomotive radiated noise is mainly caused by mechanical vibration, this suggests that the structural vibration of the locomotive does not change obviously with the increase of diesel engine gear. Noload 8 gear appears obvious peak sound pressure level in $160 \mathrm{~Hz}$, which suggests that structural resonance at 160 $\mathrm{Hz}$ makes the sound pressure level have bigger rise. Starting from $500 \mathrm{~Hz}$, with the increasing of diesel engine gear, the sound pressure level of each test point begins to have obvious distinguish, this shows that with the increasing of gear, the rise of the locomotive radiated noise mainly reflects in the high frequency part.

When the condition is load 4, point $\mathrm{D}$ and point $\mathrm{E}$ at $100 \mathrm{~Hz}$ have a higher sound pressure level, sound pressure level of point I and J are relatively low. at 100 Hz. Considering the actual test situation, D, E and I, J are not test at the same time, the locomotive's position changes during the test, the reason that the sound pressure level of $\mathrm{D}$ and $\mathrm{E}$ is high at $100 \mathrm{~Hz}$ is the vibration of locomotive causes the strong vibration of track structure.

When the condition changes to load 8 , three cooling fans hanging in cooling chamber opened, from figure 4 to 7 can be found, the sound pressure level of each point is significantly increased at each frequency. This shows that the sound radiation of cooling fan has a greater influence on the surrounding sound environment of locomotive.

\section{Cab noise test of diesel locomotive}

\subsection{Test equipment}

The analysis system of noise and vibration test includes 6 parts: SQLab II 60 channel data acquisition recorder and the front end, HMS III binaural signal collector, HPS IV digital back into the system, acoustic sensors, vibration sensors, Artemis analysis software and so on.

\subsection{Test conditions}

In the test of diesel locomotive distribution of sound pressure level of cab, according to GBT 3450-2006 Noise limits and measurement methods of railway locomotives and emu cab and actual needs, the test conditions for the diesel locomotive should be housekeeping, no-load, diesel engine gear is $0,4,8$; Diesel locomotive be housekeeping, load, diesel engine gear is $0,4,8$.

\subsection{Test points distribution}

According to GBT 3450-2006 Noise limits and measurement methods of railway locomotives and emu cab and actual needs, The distribution of the specific test points are shown in figure 8 [7].

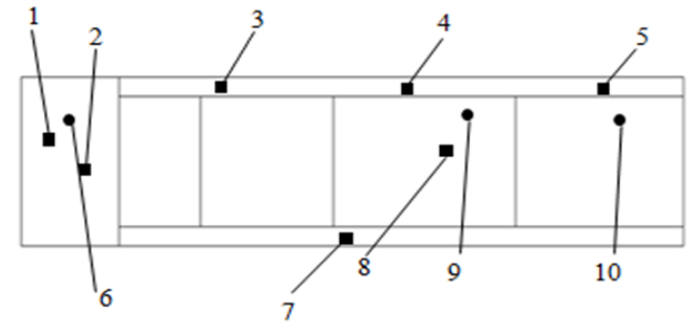

$$
\begin{array}{ll}
\text { 1- artificial head } & 2-1.2 \mathrm{~m} \text { height of the center of cab } \\
\text { 3- cooling tower } & \text { 4- diesel engine } \\
\text { 5- cooling chamber } & \text { 6- cab floor vibration } \\
\text { 7- main generator } & \text { 8- diesel engine exhaust outlet } \\
\text { 9- engine support vibration } & \text { 10- cooling fan vibration }
\end{array}
$$

Figure 8. Diesel locomotive cab test point distribution

\subsection{The test results analysis}

Can be found from figure 9, because the cab was far from the cooling chamber, when the gear is 0 and 4 , at no-load or load the difference of sound pressure level in the cab is not significant at the same gear. In the cab, $1.2 \mathrm{~m}$ height of the center, the sound pressure level all appears obvious peaks at $125 \mathrm{~Hz} 、 400 \mathrm{~Hz} 、 3150 \mathrm{~Hz}$; At gear4 gear8, there is evident peak at $1000 \mathrm{~Hz}$. In a general way, the reason that the cab appears the peak sound pressure level is to be considered the cab structure resonance or the acoustic radiation [8].

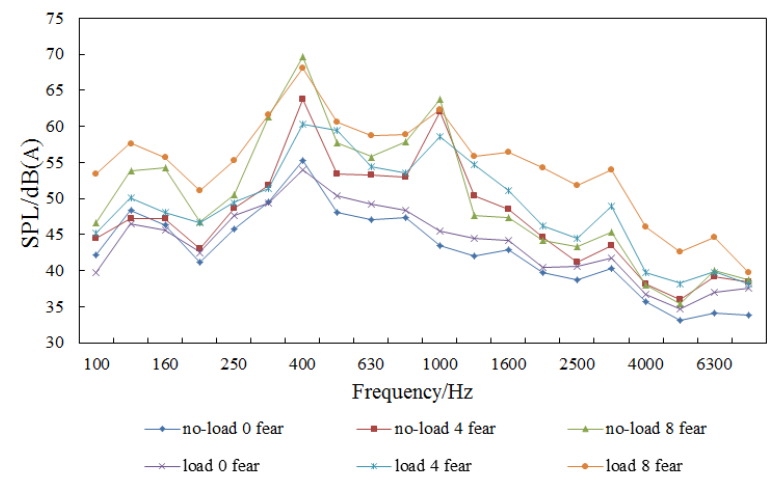

Figure 9. Each gear sound pressure level spectrum diagram of $\mathrm{cab}$

\subsection{The influence of cab vibration to cab noise}

Can be found from figure 10-15, all the gears appear obvious vibration peak at $400 \mathrm{~Hz}$, and vibration of noload is severe than vibration of load at the same gear, which is consistent with the rules of sound pressure level in the cab, this proves that part of reasons which the center of cab appears peak at $400 \mathrm{~Hz}$ is cab structure vibration.

Also in 4 and 8 gear, the vibration of the cab has obvious peak in $1000 \mathrm{~Hz}$, the vibration mainly for longitudinal vibration. Although at no-load 8 gear, longitudinal vibration is not so sever as which at load 8 gear in $1000 \mathrm{~Hz}$, but no-load 8 gear is accompanied by severe transverse vibration in $1000 \mathrm{~Hz}$, this is consistent with the rule that the sound pressure level of no-load 8 gear is slightly higher than that of load 8 gear. Vibration 
strength of no-load 4 gear is similar with that of load 8 gear, higher than that of load 4 gear, this is consistent with the rules of sound pressure level in the cab.

At $3150 \mathrm{~Hz}$, with the increase of gear, the cab of vertical, longitudinal and transverse vibration becomes acute, sound pressure level of cab at $3150 \mathrm{~Hz}$ exists evident peak.

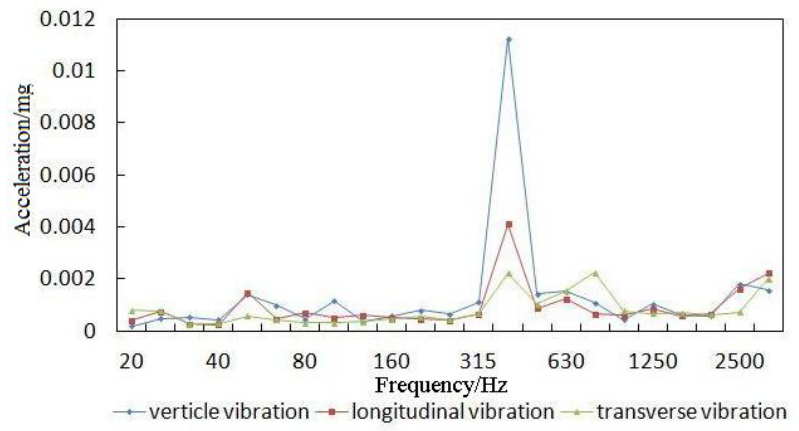

Figure 10. Vibration spectrum of cab floor at no-load 0

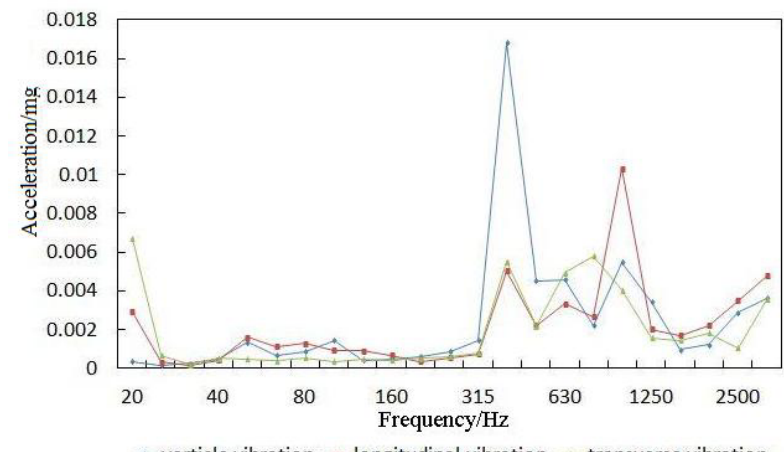

Figure 11. Vibration spectrum of cab floor at no-load 4

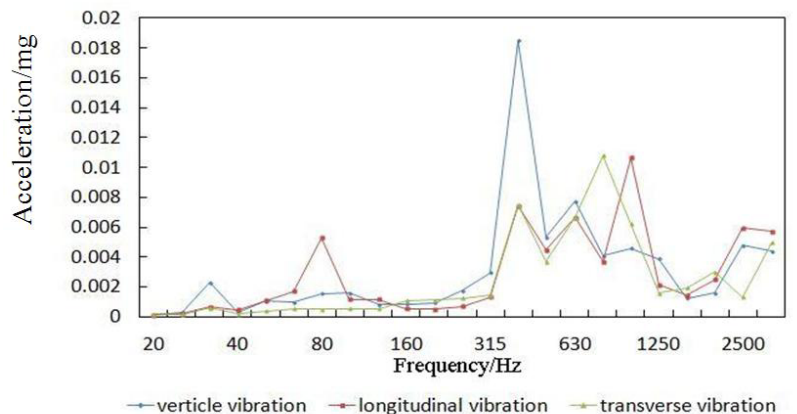

Figure 12. Vibration spectrum of cab floor at no-load 8

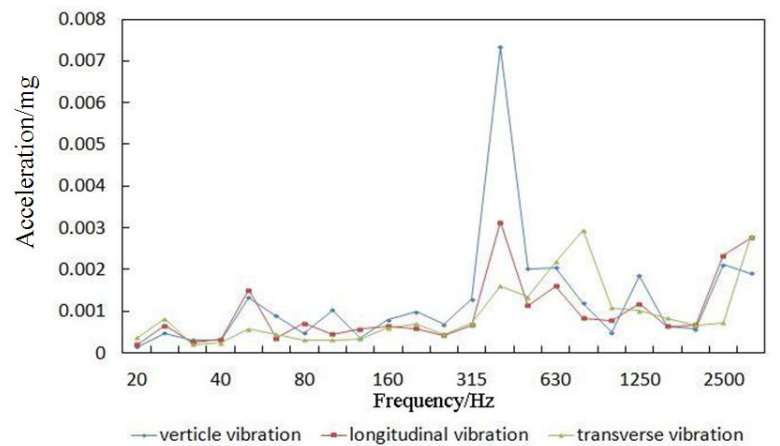

Figure 13. Vibration spectrum of cab floor at load 0

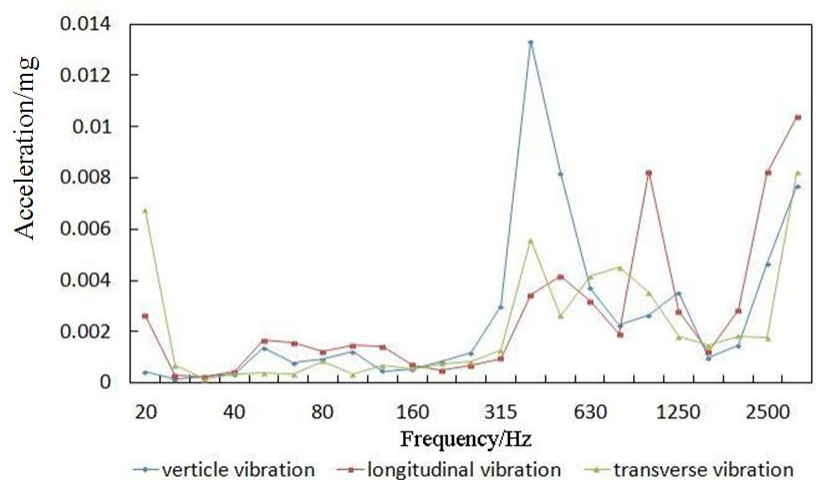

Figure 14. Vibration spectrum of cab floor at load 4

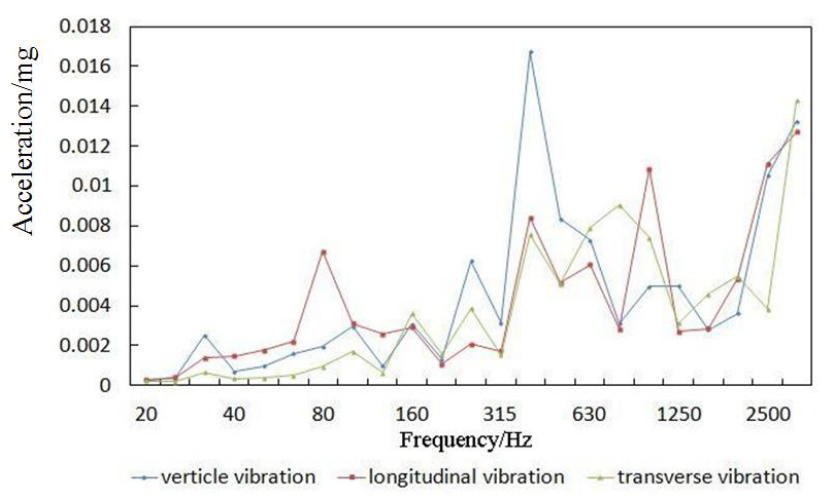

Figure 15. Vibration spectrum of cab floor at load 8

\subsection{The influence of outside noise to cab noise}

Can be found from figure 16-17, because the cab appears structural resonance at $400 \mathrm{~Hz}$ and $1000 \mathrm{~Hz}$, the peak sound pressure level at the two frequency is obvious than the peak of diesel engine. The sound pressure level tendency of cab and diesel engine is almost consistent before the $5000 \mathrm{~Hz}$, the peak sound pressure level of cab and peak of the diesel engine are in one-to-one correspondence. That illustrates that the impact of external noise source to the cab is obvious.

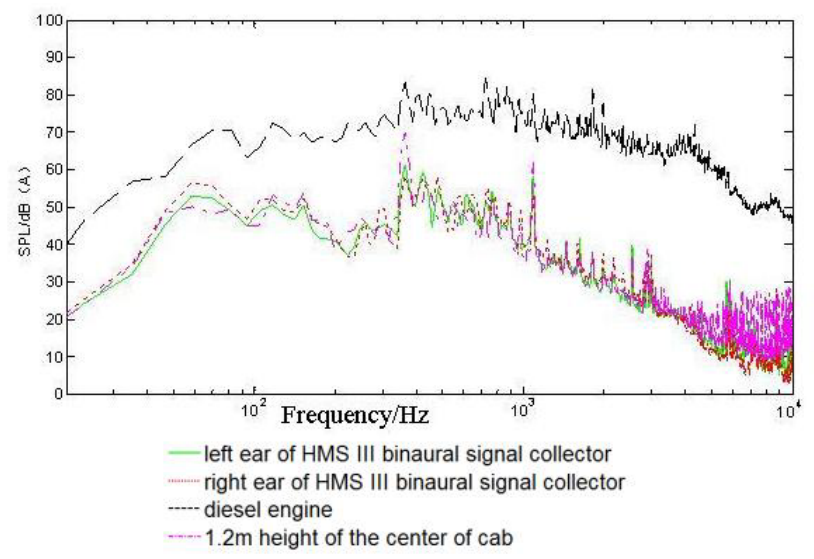

Figure 16. Engine and cab sound pressure level FFT at no-load8 


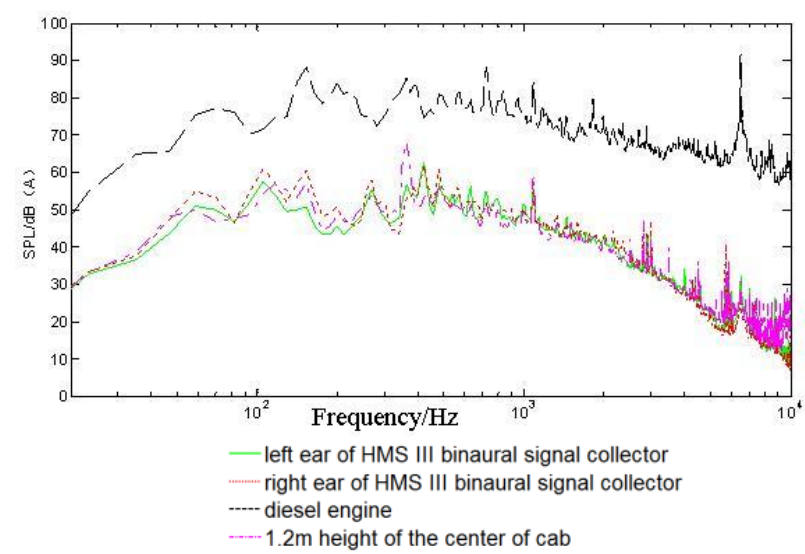

Figure 17. Engine and cab sound pressure level FFT at load8

\section{Conclusions}

(1) Among the 12 testing points of outfield, the sound pressure level of point $\mathrm{D}, \mathrm{E}, \mathrm{I}$ and $\mathrm{J}$ are bigger due to the effect of noise source.

(2) The change of working condition of locomotive mainly produces bigger change to the outfield test points at the intermediate frequency and high frequency after $400 \mathrm{~Hz}$.

(3) The opening of cooling fan makes outfield sound pressure level of each test point improved obviously

(4) The noise of the cab is mainly composed of locomotive wall vibration and the noise source: Outside noise sources affect the whole spectrum of noise of the cab, vibration makes sound pressure level of individual frequency have bigger rise.

\section{References}

1. P. S. Pang, Noise Control of Diesel Locomotive Cab (Shanghai Jiaotong University, 2006)

2. S. Xu, Modern Occupational Safety, 3(2009)

3. D. Y. Ma, Engineering Handbook of Noise And Vibrantion Control(China Machine Press, 2002)

4. Z. H. Zhang, Diesel Locomotive Overall(China Railway Press, 1991)

5. T. Y. Chen, Neijiang Technology, 30(2009)

6. AS 2377-2002 Acoustic-Methods for The Measurement of Railroad Vehicle Noise[S]

7. GB/T 3450-2006, Noise limit and measurement inside driver's cabs of railway locomotive and powered car train-sets [S]

8. S. T. Zhang, S. Q. Wang, The Internal Combustion Locomotive, 5(2002) 